\title{
Utilização de nutrientes em frangos alimentados com dietas suplementadas com fitase e níveis reduzidos de fósforo não-fítico
}

\author{
[Utilization of nutrients in broilers fed diets supplemented with phytase and reduced \\ nonphytate phosphorus levels] \\ M.C. Oliveira', R.A. Gravena ${ }^{2}$, R.H. Marques ${ }^{2}$, G.C. Guandolini ${ }^{2}$, V.M.B. Moraes ${ }^{2}$ \\ ${ }^{1}$ Faculdade de Medicina Veterinária - FESURV \\ Campus Universitário s/n \\ 75901-910 - Rio Verde, GO \\ ${ }^{2}$ Faculdade de Ciências Agrárias e Veterinárias - UNESP - Jaboticabal, SP
}

\begin{abstract}
RESUMO
Avaliaram-se a digestibilidade ileal, retenção de nutrientes e valores de energia metabolizável aparente (EMA) de dietas suplementadas com fitase e níveis reduzidos de fósforo não-fítico (FNF) para frangos de corte. Foram utilizados 330 pintos machos em delineamento em blocos ao acaso e esquema fatorial 2 × 3 com dois níveis de fitase $(0$ e $25 \mathrm{U} / \mathrm{kg})$ e três níveis de FNF (100, 85 e 70\% das exigências da ave), totalizando seis tratamentos com cinco repetições de 11 aves cada. Não houve efeito da interação FNF vs fitase e dos níveis de FNF ou fitase sobre a retenção de matéria seca e de fósforo, e a interação FNF vs fitase foi significativa para retenção de proteína bruta e coeficiente de digestibilidade ileal da matéria seca. A suplementação com fitase, independente dos níveis de FNF, melhorou o coeficiente digestibilidade ileal da proteína bruta, do cálcio e do fósforo. A retenção de cálcio e a redução dos níveis de FNF diminuíam a metabolização da energia bruta das dietas com 85 e 70\% das exigências de FNF. Dietas com nível de $70 \%$ das exigências de FNF, suplementadas com fitase, podem ser usadas para frangos de corte sem prejuízos à digestibilidade ileal e retenção da matéria seca, proteína bruta, cálcio e fósforo e à metabolização da energia bruta.
\end{abstract}

Palavras-chave: deficiência de fósforo, enzima, valor nutritivo

\begin{abstract}
The ileal digestibility, the retention of nutrients, and the apparent metabolizable energy (AME) values of diets supplemented with phytase and low levels of nonphytate phosphorus (NPP) for broilers were evaluated. Three hundred and thirty male birds were used. The experiment was designed in randomized blocks in a factorial arrangement $2 \times 3$ with two phytase levels (0 and 25U/kg) and three NPP levels (100, 85 , and $70 \%$ of the bird requirement in each phase), with five replicates of 11 broiler for each experimental unit. Effects of NPP vs phytase interaction and NPP and phytase levels on dry matter (DM) and phosphorus $(P)$ retention were not observed; but significant effects of NPP vs phytase on crude protein (CP) retention and DM ileal digestibility coefficient (IDC). Phytase supplementation, independently of NPP levels, improved CPIDC, CaIDC, PIDC, and Ca retention and the lower NPP levels decreased the gross energy metabolization in diets with 85 and $70 \%$ of NPP requirements. Diets with NPP level corresponding to $70 \%$ of the bird requirements, supplemented with phytase, can be used for broiler with no negative effect on ileal digestibility and retention of dry matter, crude protein, calcium and phosphorus, and on apparent metabolizable energy.
\end{abstract}

Keywords: enzymes, nutritive value, phosphorus deficiency

Recebido em 31 de agosto de 2007

Aceito em 17 de março de 2008

E-mail: cristina@fesurv.br 


\section{INTRODUÇÃO}

Os principais ingredientes em dietas de aves são grãos de cereais ou produtos de sementes (farelos de sementes oleaginosas e subprodutos de grãos). O fitato compreende de 1 a $5 \%$ do peso destes ingredientes e, como tal, é a principal fonte natural de fósforo $(\mathrm{P})$ no alimento animal já que contém, aproximadamente, $28,2 \%$ de $\mathrm{P}$ (Kornegay, 2001). O fitato não é digerido no trato gastrintestinal dos monogástricos devido a pouca ou nenhuma atividade de fitase intestinal e, como resultado, as dietas usualmente são suplementadas com fontes de P inorgânico.

Em valores de $\mathrm{pH}$ normalmente encontrados nos alimentos e no trato gastrintestinal, o fitato apresenta cargas fortemente negativas e forma complexos muito estáveis com cátions di- e trivalentes tais como $\mathrm{Zn}, \mathrm{Cu}, \mathrm{Ni}, \mathrm{Co}, \mathrm{Mn}, \mathrm{Ca}$ e $\mathrm{Fe}$, em ordem decrescente de estabilidade (Maenz, 2001; Angel et al., 2002), reduzindo, assim, a disponibilidade desses minerais complexados, bem como a do $\mathrm{P}$ fítico para $\mathrm{O}$ animal. Além de se complexar com macro e microminerais, intrínsecos nas sementes e aqueles adicionados às dietas, o fitato pode formar complexos com proteínas e amidos que impedem sua degradação e inibir várias enzimas importantes in vitro tais como as proteases (Kornegay, 2001; Peter e Baker, 2001). A possibilidade do uso de fitases microbianas nas dietas permite aumentar a disponibilidade do $\mathrm{P}$ fítico e de outros minerais (Brenes et al., 2003), melhora a eficiência de utilização de proteínas e aminoácidos e da energia (Ravindran et al., 2001) em monogástricos.

As fitases são enzimas que hidrolisam o ácido fítico (mio-inositol hexafosfato) e seus sais (fitato), produzindo inositol, inositol monofosfato e P inorgânico (Casey e Walsh, 2004; Vats e Banerjee, 2004). A hidrólise do fitato melhora a digestibilidade da proteína bruta, matéria seca e energia bruta (Cowieson et al., 2004; Rutherfurd et al., 2004; Wu et al., 2004) bem como de minerais como o cálcio e o P. Entretanto, há relatos de que a inclusão de fitase em dietas para frangos não melhora a digestibilidade de alguns nutrientes (Peter e Baker, 2001; Pourreza e Classen, 2001; Juanpere et al., 2004; Silversides et al., 2004).
Este experimento foi conduzido para determinar a digestibilidade ileal e a retenção de matéria seca (MS), proteína bruta (PB), energia bruta, cálcio $(\mathrm{Ca})$ e fósforo $(\mathrm{P})$ em frangos alimentados com dietas suplementadas com fitase e com níveis reduzidos de fósforo não-fítico.

\section{MATERIAL E MÉTODOS}

Foram utilizados 330 pintos machos Cobb com 13 dias de idade, alojados em gaiolas de metabolismo, equipadas com bebedouros e comedouros lineares. O período experimental teve duração de 10 dias, sendo sete dias de adaptação às dietas experimentais e às gaiolas e três de coleta parcial de excretas.

$\mathrm{O}$ delineamento experimental foi em blocos ao acaso em arranjo fatorial $2 \times 3$ com dois níveis $(0$ e $25 \mathrm{U} / \mathrm{kg}$ ) de fitase e três níveis de fósforo nãofítico (FNF) (100, 85 e 70\% das exigências da ave correspondendo aos níveis de $0,45,0,38$ e $0,31 \%$ de FNF, respectivamente) e cinco repetições de 11 aves por unidade experimental. A fitase utilizada, contendo atividade de $250 \mathrm{U} / \mathrm{g}$ e obtida por fermentação por meio de fungos (Aspergillus niger), foi adicionada às dietas na proporção de $100 \mathrm{~g} / \mathrm{t}$. As dietas experimentais (Tab. 1), formuladas de acordo com Rostagno et al. (2000), foram isonutritivas, exceto pelos níveis de FNF. A água e as dietas foram fornecidas à vontade.

Até 13 dias de idade, todas as aves receberam dietas experimentais sem indicador ou fitase e com teor de FNF correspondendo a 100\% das exigências. Quando as aves completaram 13 dias de idade, foram alojadas nas gaiolas e passaram a receber as dietas experimentais misturadas com $0,5 \%$ de óxido crômico $\left(\mathrm{Cr}_{2} \mathrm{O}_{3}\right)$. De 20 a 22 dias de idade, foi realizada a coleta parcial de excretas, com intervalo de 12 horas.

Para a coleta das excretas, foram selecionados seis locais na bandeja onde as excretas foram coletadas. Posteriormente, as amostras foram acondicionadas em saco plástico e congeladas. Aos 23 dias de idade, todas as aves de cada repetição foram sacrificadas por deslocamento cervical e imediatamente seccionadas para obtenção da digesta do íleo terminal, desde $4 \mathrm{~cm}$ antes da junção íleo-cecólica até $20 \mathrm{~cm}$ em direção ao jejuno. Este segmento foi seccionado transversalmente e seu conteúdo, retirado e 
acondicionado dentro de recipiente com tampa. As digestas coletadas foram identificadas e armazenadas em congelador. Após isso, as amostras de excretas e digestas foram descongeladas, homogeneizadas e passaram pela pré-secagem a $65^{\circ} \mathrm{C}$ por 48 horas em estufa de ventilação forçada, sendo, posteriormente, moídas em moinho de bola. Todas as análises das excretas, digestas e dietas foram realizadas utilizando a metodologia descrita por Silva e Queiroz (2002). Com os resultados das análises laboratoriais, calcularam-se os coeficientes de digestibilidade ileal (CDI) e retenção da matéria seca (MS), proteína bruta (PB), energia bruta $(\mathrm{EB})$, fósforo $(\mathrm{P})$ e cálcio $(\mathrm{Ca})$ e os valores de energia metabolizável aparente (EMA) com base nos níveis de cromo nas dietas, digestas e excretas e no fator de indigestibilidade, como descrito por Dilger et al. (2004).

A análise estatística foi realizada por meio do programa SAEG (Sistema..., 2001) e, para a comparação das médias, utilizou-se o teste Tukey ao nível de 5\% de probabilidade.

Tabela 1. Composição percentual e calculada das dietas experimentais com fitase e níveis reduzidos de fósforo não-fítico (FNF)

\begin{tabular}{lccc}
\hline \multirow{2}{*}{ Ingrediente $(\mathrm{kg})$} & \multicolumn{3}{c}{ FNF (\% das exigências) } \\
\cline { 2 - 4 } Milho moído & 100 & 85 & 70 \\
Farelo de soja & 56,78 & 57,05 & 57,32 \\
Óleo de soja & 35,96 & 35,91 & 35,86 \\
Fosfato bicálcico & 3,01 & 2,92 & 2,83 \\
Calcário calcítico & 1,80 & 1,44 & 1,08 \\
DL-metionina 99\% & 0,99 & 1,22 & 1,45 \\
L-lisina 78,80\% & 0,03 & 0,03 & 0,03 \\
Sal & 0,15 & 0,15 & 0,15 \\
Inerte 1 ( & 0,45 & 0,45 & 0,45 \\
Antioxidante & 0,01 & 0,01 & 0,01 \\
Suplemento mineral e vitamínico ${ }^{2}$ & 0,02 & 0,02 & 0,02 \\
\hline & 0,80 & 0,80 & 0,80 \\
\hline Proteína bruta (\%) & & & \\
Energia metabolizável (kcal/kg) & Composição calculada & 21,40 & 21,40 \\
Cálcio (\%) & 21,40 & 3000 & 3000 \\
Fósforo não-fítico (\%) & 3000 & 0,96 & 0,96 \\
Lisina total (\%) & 0,96 & 0,38 & 0,31 \\
Metionina total (\%) & 0,45 & 1,26 & 1,26 \\
\hline
\end{tabular}

composto por caulim ou fitase.

${ }^{2}$ cada kg contém: vit.A: $1500000 \mathrm{UI}$; vit. $\mathrm{D}_{3}$ : $285000 \mathrm{UI}$; vit.E: $1350 \mathrm{mg}$; vit.K $\mathrm{K}_{3}$ : $230 \mathrm{mg}$; vit. $\mathrm{B}_{1}$ : $115 \mathrm{mg}$; vit. $\mathrm{B}_{2}$ : $1150 \mathrm{mg}$; vit. $\mathrm{B}_{12}$ : 2000mcg; ácido nicotínico: 4800mg; ácido pantotênico: $1240 \mathrm{mg}$, piridoxina: 230mg; biotina: 12mg; ácido fólico: 115mg; colina: 85g; metionina: 170g; Fe: 6300mg; Cu: 9400mg; Mn: 9400mg; Zn: 7819mg; I: $160 \mathrm{mg}$; Se: $23 \mathrm{mg}$; antioxidante: $20 \mathrm{~g}$; promotor de crescimento:5,4g; anticoccidiano: $6,4 \mathrm{~g}$.

\section{RESULTADOS E DISCUSSÃO}

Não houve efeito $(\mathrm{P}>0,05)$ da interação FNF vs fitase e dos níveis de FNF ou fitase sobre a retenção de MS. A interação FNF vs fitase foi significativa para retenção de $\mathrm{PB}(\mathrm{P}<0,03)$ e CDIMS $(\mathrm{P}<0,007)$. A suplementação com fitase, independente dos níveis de FNF, melhorou o CDIPB $(\mathrm{P}<0,008)$ e a redução dos níveis de FNF diminuíu a metabolização da energia bruta $(\mathrm{P}<0,04)$ das dietas com 85 e $70 \%$ das exigências de FNF (Tab. 2).
O menor valor de CDIMS foi obtido em aves do tratamento com FNF correspondente a $100 \%$ das exigências e sem fitase e foi $5,60 \%$ e $6,12 \%$ menor que os valores obtidos com dietas sem fitase e com FNF de 85 e $70 \%$. Com a inclusão de fitase na dieta com $100 \%$ de FNF, o CIDMS melhorou em 9\%. A redução no consumo de ração em animais com deficiência de $\mathrm{P}$ é comum e, embora a causa não esteja bem estabelecida, é possível que a oxidação fosforilativa nas mitocôndrias seja inibida e diminua a produção de ATP com conseqüente aumento dos níveis de 
glicose no sangue (Rapoport e Guest, 1938; Bishop e Williams, 1958; Sugiura et al., 2000; 2004). O aumento da glicose sanguínea inibe o apetite pelo estímulo no centro da saciedade e por inibição do centro da fome (Duke, 1996). Como aves submetidas à deficiência de $\mathrm{P}$ consomem menos ração, é provável que a digesta tenha permanecido maior tempo no intestino delgado, melhorando a digestibilidade dos nutrientes em geral e com a inclusão da fitase, mesmo na dieta com $100 \%$ de FNF, houve maior aporte de nutrientes para absorção já que o fitato se liga também às proteínas, lipídios e amido.

Tabela 2. Retenção (R) e coeficientes de digestibilidade ileal (CDI) da matéria seca (MS) e da proteína bruta $(\mathrm{PB})$ e valores de energia metabolizável aparente (EMA) de dietas suplementadas com fitase e com níveis reduzidos de fósforo não-fítico (FNF)

\begin{tabular}{|c|c|c|c|c|c|c|}
\hline \multirow{2}{*}{ Parâmetro } & \multirow{2}{*}{ Fitase } & \multicolumn{3}{|c|}{ FNF (\% das exigências) } & \multirow{2}{*}{ Média } & \multirow{2}{*}{$\mathrm{CV}(\%)$} \\
\hline & & 100 & 85 & 70 & & \\
\hline \multirow[t]{3}{*}{ RMS (\%) } & 0 & 79,25 & 76,34 & 79,10 & 78,23 & \\
\hline & 25 & 79,02 & 78,53 & 77,27 & 78,27 & \\
\hline & Média & 79,13 & 77,44 & 78,18 & & 2,45 \\
\hline \multirow[t]{3}{*}{ CDIMS (\%) } & 0 & $74,09 \mathrm{Bb}$ & $78,49 \mathrm{Aa}$ & $78,92 \mathrm{Aa}$ & 77,16 & \\
\hline & 25 & $80,73 \mathrm{Aa}$ & $80,00 \mathrm{Aa}$ & $77,92 \mathrm{Aa}$ & 79,55 & \\
\hline & Média & 77,41 & 79,24 & 78,42 & & 3,12 \\
\hline \multirow[t]{3}{*}{ RPB (\%) } & 0 & $73,27 \mathrm{Aa}$ & $72,04 \mathrm{Aa}$ & $67,51 \mathrm{Bb}$ & 70,94 & \\
\hline & 25 & $72,98 \mathrm{Aa}$ & $72,10 \mathrm{Aa}$ & $72,95 \mathrm{Aa}$ & 72,67 & \\
\hline & Média & 73,13 & 72,07 & 70,23 & & 3,48 \\
\hline \multirow[t]{3}{*}{ CDIPB (\%) } & 0 & 86,83 & 87,16 & 87,43 & $87,14 \mathrm{~B}$ & \\
\hline & 25 & 89,75 & 88,52 & 88,17 & $88,81 \mathrm{~A}$ & \\
\hline & Média & 88,29 & 87,84 & 87,80 & & 1,76 \\
\hline \multirow[t]{3}{*}{ EMA (kcal/kg MS) } & 0 & 3596 & 3530 & 3582 & 3570 & \\
\hline & 25 & 3653 & 3563 & 3492 & 3569 & \\
\hline & Média & $3625 a$ & $3547 b$ & $3537 b$ & & 2,19 \\
\hline
\end{tabular}

$\mathrm{CV}=$ coeficiente de variação.

Médias seguidas por letras diferentes maiúsculas nas colunas e minúsculas nas linhas diferem entre si pelo teste Tukey $(\mathrm{P}<0,05)$.

A retenção de PB foi menor nas aves alimentadas a dietas com níveis de FNF correspondentes a $70 \%$ das exigências e sem fitase, porém, a inclusão de fitase nestas dietas foi suficiente para aumentar a retenção de $\mathrm{PB}$ em $7,46 \%$ dessas dietas e o CDIPB melhorou em $2 \%$ com a inclusão de fitase, independente dos níveis de FNF. Os maiores valores de retenção e de digestibilidade ileal da proteína bruta ocorreram porque a fitase hidrolisa os complexos formados pelo fitato e proteína e/ou aminoácidos e aumenta a disponibilidade desses nutrientes para absorção no intestino.

Os resultados observados no presente experimento são semelhantes aos de Lan et al. (2002) e Wu et al. (2004) que, ao avaliarem dietas deficientes em FNF em 0,34\% e 0,30\%, respectivamente, constataram melhores coeficientes de digestibilidade da PB e MS atribuídos à suplementação das dietas com fitase. Cowieson et al. (2004), Dilger et al. (2004) e
Akyurek et al. (2005) testaram dietas com diferentes níveis de fitase e de FNF e não observaram efeito sobre a digestibilidade da matéria seca e da proteína bruta.

Como o P participa nos processos metabólicos e de absorção de nutrientes, é possível que a redução dos valores de EMA possa ser resultado da menor capacidade dessas aves em metabolizar e reter os nutrientes. Além disso, a ave ingere menor quantidade de água em razão da redução no consumo de alimentos (Juanpere et al., 2004) e, sendo assim, pode ter havido concentração dos componentes da urina causando a redução nos valores de EMA. Namkung e Leeson (1999) estudaram níveis de 0,45 e $0,35 \%$ de FNF, com e sem fitase, e relataram que a inclusão da enzima na dieta melhorou a EMA em 1\%. Juanpere et al. (2004) avaliaram os níveis de 0,45 e $0,27 \%$ de FNF, também com e sem fitase, e verificaram que a EMA diminuiu com a redução do FNF. Pourreza e Classen (2001) e Onyango et al. (2005), ao avaliarem dietas com níveis de fitase que variavam 
de 0 a $1200 \mathrm{U} / \mathrm{kg}$ e com $0,27 \%$ de FNF, respectivamente, não encontraram diferenças nos valores de EMA em função dos níveis de enzima e/ou FNF.

Não houve efeito $(\mathrm{P}>0,05)$ da interação $\mathrm{FNF} v s$ fitase e dos níveis de FNF ou fitase sobre a retenção de $\mathrm{P}$, provavelmente porque tenha ocorrido maior absorção de P no intestino grosso, como forma de preservar mais $\mathrm{P}$ no organismo para as reações fisiológicas nas aves alimentadas com dietas sem fitase e com níveis reduzidos de FNF (Brenes et al., 2003). A adição de fitase às dietas melhorou os valores de retenção de $\mathrm{Ca}(\mathrm{P}<0,001)$ e os $\mathrm{CDICa}$ $(\mathrm{P}<0,001)$ e CDIP $(\mathrm{P}<0,002) \quad($ Tab. 3). Estes resultados refletem o efeito da hidrólise do fitato, tornando os minerais mais disponíveis para absorção. A fitase, ao hidrolisar os complexos fitato-minerais, libera não somente $\mathrm{P}$, mas também $\mathrm{Ca}$ para que sejam absorvidos. Não houve, entretanto, efeito sobre a retenção de P. Estes resultados são semelhantes aos de Tejedor et al. (2001), Viveros et al. (2002) e Rutherfurd et al. (2004) que trabalharam com níveis de FNF que variaram de 0,33 a $0,37 \%$ e níveis de fitase de 0 , 500 e $750 \mathrm{U} / \mathrm{kg}$ de dieta.

Tabela 3. Retenção e coeficientes de digestibilidade ileal $(\mathrm{CDI})$ do cálcio $(\mathrm{Ca})$ e fósforo $(\mathrm{P})$ de dietas suplementadas com fitase e com níveis reduzidos de fósforo não-fítico (FNF)

\begin{tabular}{cllcccc}
\hline \multirow{2}{*}{ Parâmetro } & \multicolumn{1}{c}{ Fitase } & \multicolumn{2}{c}{ FNF (\% das exigências) } & \multirow{2}{*}{ Média } & \multirow{2}{*}{ CV (\%) } \\
\cline { 3 - 5 } RCa (\%) & 0 & 56,85 & 58,55 & 52,41 & $55,94 \mathrm{~b}$ & \\
& 25 & 63,85 & 63,75 & 60,54 & $62,72 \mathrm{a}$ & \\
& Média & 60,35 & 61,15 & 56,47 & & 7,26 \\
CDICa (\%) & 0 & & & & & \\
& 25 & 37,51 & 46,01 & 41,98 & $41,84 \mathrm{~b}$ & \\
& Média & 53,22 & 53,01 & 62,87 & $56,39 \mathrm{a}$ & \\
& & 45,37 & 49,51 & 52,43 & & 15,34 \\
RP (\%) & 0 & & & & & \\
& 25 & 62,97 & 66,45 & 68,53 & 65,98 & \\
& Média & 67,37 & 68,90 & 67,52 & 67,93 & \\
CDIP (\%) & & 65,17 & 67,67 & 68,03 & & 5,26 \\
& 0 & & & & & \\
& 25 & 55,43 & 58,09 & 55,53 & $56,35 \mathrm{~b}$ & \\
& Média & 63,37 & 63,24 & 63,19 & $63,27 \mathrm{a}$ & \\
\hline CV & 59,41 & 60,66 & 59,36 & & 8,73 \\
\hline
\end{tabular}

$\mathrm{CV}=$ coeficiente de variação.

Médias seguidas por letras diferentes nas colunas diferem entre si pelo teste Tukey $(\mathrm{P}<0,05)$.

\section{CONCLUSÃO}

Dietas para frangos de corte com FNF correspondendo a $70 \%$ das exigências, suplementadas com fitase, podem ser utilizadas, sem prejuízos à digestibilidade da matéria seca, proteína bruta, $\mathrm{Ca}$ e $\mathrm{P}$ e à metabolização da energia bruta.

\section{AGRADECIMENTOS}

À Fundação de Apoio à Pesquisa do Estado de São Paulo (FAPESP), Alltech do Brasil Agroindustrial Ltda e Fundação para o Desenvolvimento da UNESP (FUNDUNESP) pelo apoio financeiro e à Agroceres Nutrição Animal pelas análises de fósforo das dietas, digestas e excretas .

\section{REFERÊNCIAS BIBLIOGRÁFICAS}

AKYUREK, H.; SENKOYLU, N.; OZDUVEN, M.L. Effect of microbial phytase on growth performance and nutrients digestibility in broilers. Pak. J. Nutr., v.4, p.2226,2005

ANGEL, R.; TAMIM, N.M.; APPLEGATE, T.J. et al. Phytic acid chemistry: influence on phytin-phosphorus availability and phytase efficacy. J. Appl. Poult. Res., v.11, p.471-480, 2002.

BISHOP, C.; WILLIAMS, C.B. Diminished blood ATP concentrations induced in the chick by dietary aluminum hydroxide gel. Fed. Proc., v.17, p.15, 1958.

BRENES, A. VIVEROS, A.; ARIJA, I. et al. The effect of citric acid and microbial phytase on mineral utilization in broiler chicks. Anim. Feed Sci. Technol., v.110, p.201$219,2003$. 
CASEY, A.; WALSH, G. Identification and characterization of a phytase of potential commercial interest. J. Biotech., v.110, p.313-322, 2004.

COWIESON, A.J.; ACAMOVIC, T.; BEDFORD, M.R. The effects of phytase and phytic acid on the loss of endogenous amino acids and minerals from broiler chickens. Brit. Poult. Sci., v.45, suppl.1, p.101-108, 2004.

DILGER, R.N.; ONYANGO, E.M.; SANDS, J.S.; ADEOLA, O. Evaluation of microbial phytase in broiler diets. Poult. Sci., v.83, p.962-970, 2004.

DUKE, G.E. Digestão nas aves. In: SWENSON, M.J.; REECE, W.O. (Eds) Dukes - Fisiologia dos animais domésticos. 11.ed. Rio de Janeiro: Guanabara Koogan, 1996. 856p.

JUANPERE, J.; PÉREZ-VENDRELL, A.M.; BRUFAU, J. Effect of microbial phytase on broilers fed barley-based diets in the presence or not of endogenous phytase. Anim. Feed Sci. Technol., v.115, p.265-279, 2004.

KORNEGAY, E.T. Digestion of phosphorus and other nutrientes: the role of phytases and factors influencing their activity. In: BEDFORD, M.R.; PARTRIDGE, G.G. (Eds) Enzymes in farm animal nutrition. Wallingford: Cab Publishing, 2001. p. 237-272.

LAN, G.Q.; ABDULLAH, N.; JALALUDIN, S. et al. Efficacy of supplementation of a phytase-producing bacterial culture on the performance and nutrient use of broiler chickens fed corn-soybean meal diets. Poult. Sci., v.1, p.1522-1532, 2002.

MAENZ, D.D. Enzymatic characteristics of phytases as they relate to their use in animals feeds. In: BEDFORD, M.R.; PARTRIDGE, G.G. (Eds) Enzymes in farm animal nutrition. Wallingford: Cab Publishing, 2001. p.61-84.

NAMKUNG, H.; LEESON, S. Effect of phytase enzyme on dietary nitrogen-corrected apparent metabolizable energy and the ileal digestibility of nitrogen and amino acids in broiler chicks. Poult. Sci., v.78, p.1317-1319, 1999.

ONYANGO, E.M.; BEDFORD, M.R.; ADEOLA, O. Efficacy of an evolved Escherichia coli phytase in diets of broiler chicks. Poult. Sci., v.84, p.248-255, 2005.

PETER, C.M.; BAKER, D.H. Microbial phytase does not improve protein-amino acid utilization in soybean meal fed to young chickens. J. Nutr., v.131, p.1792-1797, 2001 .

POURREZA, J.; CLASSEN, H.L. Effects of supplemental phytase and xylanase on phytate phosphorus degradation, ileal protein and energy digestibility of a corn-soybean-wheat bran diets in broiler chicks. J. Agric. Sci. Tech., v.3, p.19-25, 2001.
RAPOPORT, S.; GUEST, G.M. Changes of organic acidsoluble phosphorus, diphosphoglycerate, adenosine triphosphate, and inorganic phosphorus in the blood cells of rats during the development and healing of rickets. $J$. Biol. Chem., v.126, p.749-761, 1938.

RAVINDRAN, V.; SELLE, P.H.; RAVINDRAN, G. et al. Microbial phytase improves performance, apparent metabolizable energy, and ileal amino acid digestibility of broilers fed a lysine-deficient diet. Poult. Sci., v.80, p.338-344, 2001.

ROSTAGNO, H.S.; ALBINO, L.F.T.; DONZELE, J.L. et al. Tabelas brasileiras para aves e suinos. Composição de alimentos e exigências nutricionais. 2.ed. Viçosa: UFV, 2000 .

RUTHERFURD, S.M.; CHUNG, T.K.; MOREL, P.C.H. et al. Effect of microbial phytase on ileal digestibility of phytate phosphorus, total phosphorus, and amino acids in a low-phosphorus diet for broilers. Poult. Sci., v.83, p.6168, 2004.

SILVA, D.J.; QUEIROZ, C.A. Análise de alimentos: métodos químicos e biológicos. 3.ed. Viçosa: UFV, 2002.

SILVERSIDES, F.G.; SCOTT, T.A.; BEDFORD, M.R. The effect of phytase enzyme and level on nutrient extraction by broilers. Poult. Sci., v.83, p.985-989, 2004.

SISTEMA de análises estatísticas - SAEG. Versão 8.0. Viçosa: UFV, 2001. 150p.

SUGIURA, S.H.; DONG, F.M.; HARDY, R.W. Primary responses of rainbow trout to dietary phosphorus concentrations. Aquac. Nutr., v.6, p.235-245, 2000.

SUGIURA, S.H.; HARDY, R.W.; ROBERTS, R.J. The pathology of phosphorus deficiency in fish - a review. $J$. Fish Dis., v.27, p.255-265, 2004.

TEJEDOR, A.A.; ALBINO, L.F.T.; ROSTAGNO, H.S. et al. Efeito da adição da enzima fitase sobre o desempenho e a digestibilidade ileal de nutrientes. Rev. Bras. Zootec., v.30, p.802-808, 2001.

VATS, P.; BANERJEE, U.C. Production studies and catalytic properties of phytases (myoinositolhexakisphosphate phosphohydrolases): an overview. Enzyme Microb. Technol., v.35, p.3-14, 2004.

VIVEROS, A.; BRENES, A.; ARIJA, I. et al. Effects of microbial phytate supplementation on mineral utilization and serum enzyme activities in broiler chicks fed different level of phosphorus. Poult. Sci., v.81, p.1172-1183, 2002.

WU, Y.B.; RAVINDRAN, V.; HENDRIKS, W.H. et al. Evaluation of a microbial phytase, produced by solid state fermentation, in broiler diets. II. Influence on phytate hydrolysis, apparent metabolizable energy, and nutrient utilization. J. Appl. Poult. Res., v.13, p.561-569, 2004. 